\title{
Verification of the protective steam curtain model by means of experiment's results
}

\author{
Rail Nasibullin ${ }^{1, *}$, Sergey Valeyev ${ }^{1}$, and Ainur Galeyev ${ }^{1}$ \\ ${ }^{1}$ Kazan National Research University, mechanical engineering for chemical industry department, \\ 420015 Kazan, Russia
}

\begin{abstract}
To protect the technological furnaces of the oil and gas industry from the penetration into their combustion zone combustible gases that are accidentally released at the production site, steam curtains are used. In the open press, there are practically no methods that allow to evaluate the efficiency of steam curtains, so the solution of this issue seems to be topical. In this paper, we checked the adequacy of the mathematical model developed by the authors of this article. This model describes the operation of the curtain, the movement of the vapor-gas cloud in space, and the scattering of the cloud by the curtain. The verification was carried out by comparing the results of the simulation with the results of laboratory experiments of third-party authors.
\end{abstract}

\section{Introduction}

Oil necessary to heat up to certain temperatures in its preparation and processing. This task is performed by tubular technological furnaces [1]. Oil, moving through the pipes inside the furnace body, is heated by the hot combustion products of the fuel, which is fed and burned by the furnace burners. In terms of industrial safety, process furnaces incur an increased risk of hazardous situations, because in the oil and gas industry production areas, flammable gases such as liquefied propane are produced, handled or stored. The fuel vaporgas cloud formed as a result of emergency depressurization of the tank, reaching the furnace, can cause an explosion and followed by the development of a fire. In order to reduce or completely eliminate the probability of occurrence of these cases, steam curtains are used around the furnaces, which are designed to block the penetration of combustible gases from outside into the furnace.

Steam curtains are barrier of the steam flows with certain height, formed around the protected object. Flows are created using a pipeline with an upper perforation, inside which water vapor is contained under a certain pressure and temperature. Escaping through the holes of the pipe located at ground level along the perimeter of the furnace, steam flow creates a curtain that is intended to delay the movement of the combustible cloud into the combustion zone of the furnace. The vapor streams of the curtain, in addition to shielding,

\footnotetext{
${ }^{*}$ Corresponding author: rail90ongp@yandex.ru
} 
also neutralize the dangerous combustible cloud, raising it above the level of the protected object, intensively dissipating at altitude.

There are a small number of documents and standards [2], which contains methods and recommendations for the design of curtains. But, unfortunately, these methods are not sufficiently parameterized and they do not allow to reveal the effectiveness of the designed curtains. In addition, dangerous incidents can develop in a very wide range of variables: the amount of emitted into the atmosphere liquefied gas, the weather conditions, the nature of industrial buildings, etc. Therefore, the authors of this article developed a method that would allow quantifying the effectiveness of steam curtains protection, taking into account all external factors that affect the development of the accident. The basis of the method for evaluating the protective ability of steam curtains is a mathematical model in the form of a system of differential equations with certain initial and boundary conditions, and the accuracy of the calculation results depends on how correctly they are set. Therefore, in this paper, a comparison was made between the results of a laboratory experiment scattering of a gas cloud by a steam curtain, performed by external authors in real scale [3], with the results of a numerical experiment calculated according to the mathematical model, completely identical to the original real data.

\section{Initial data of the experiment}

The paper [3] contains the conducting conditions and the results of a laboratory experiment on the investigation of the protective ability of a steam curtain. In the laboratory installation, shown in Figure 1, a series of three experiments was carried out to release carbon dioxide at a flow rate of $15.6 \mathrm{l} / \mathrm{s}$ using vessels and a device, attached to them, that equalized the gas flows. In the first experiment, the gas propagated in space without a steam barrier, in the second and third studies - with operating curtain with vapor pressure values in the supply pipeline of $3 \mathrm{kgf} / \mathrm{cm}^{2}$ and $5 \mathrm{kgf} / \mathrm{cm}^{2}$. With the help of a blower in the area of the barrier, wind was created at a speed of $1,5 \mathrm{~m} / \mathrm{s}$. The pipeline forming the vapor barrier is located at a distance of 4 meters from the place where the gas exits to the outside, in a small recess of the surface of the site so that the steam curtain starts from the floor level of the laboratory installation. The steam flows are discharged upwards by means of nozzles with a diameter of $8 \mathrm{~mm}$ installed on the pipe, with a nozzle spacing of $20 \mathrm{~cm}$. The carbon dioxide in the experiments was released until the moment when its concentration on the leeward side of the curtain became constant (independent of time). Sensors measuring the concentration of carbon dioxide are located 1 meter perpendicular to the line of the curtain in the direction of the wind, at a height of $5 \mathrm{~cm}$ from the floor of the installation.

The mathematical model developed for the purpose of analyzing the operability of the steam curtain is a system of differential equations conservation of mass, energy and momentum, supplemented by the equations of the $k-\varepsilon$ model of turbulence. The solution of these equations was carried out numerically, based on the finite volume method, by means of the specialized CFD program Fluent [4]. All the geometric characteristics of the experiment were taken into account by creating a three-dimensional grid with dimensions equal to the spatial magnitudes of the laboratory setup. The wind was modeled by setting on the enter surface of the calculated region the boundary condition of a mass flow of air at a speed of $1.5 \mathrm{~m} / \mathrm{s}$. Roughness on the surface of the floor was taken as the height of the roughness for the concrete material. The boundary condition of the zero excess pressure was established on the exit surface, the symmetry condition - on the lateral faces, perpendicular to the flow. The device releasing carbon dioxide was simulated by isolating a group of cells on the calculated grid according to its actual dimensions $(20 \mathrm{~cm} \times 20 \mathrm{~cm})$ according to the location on the laboratory installation (Fig. 1). 


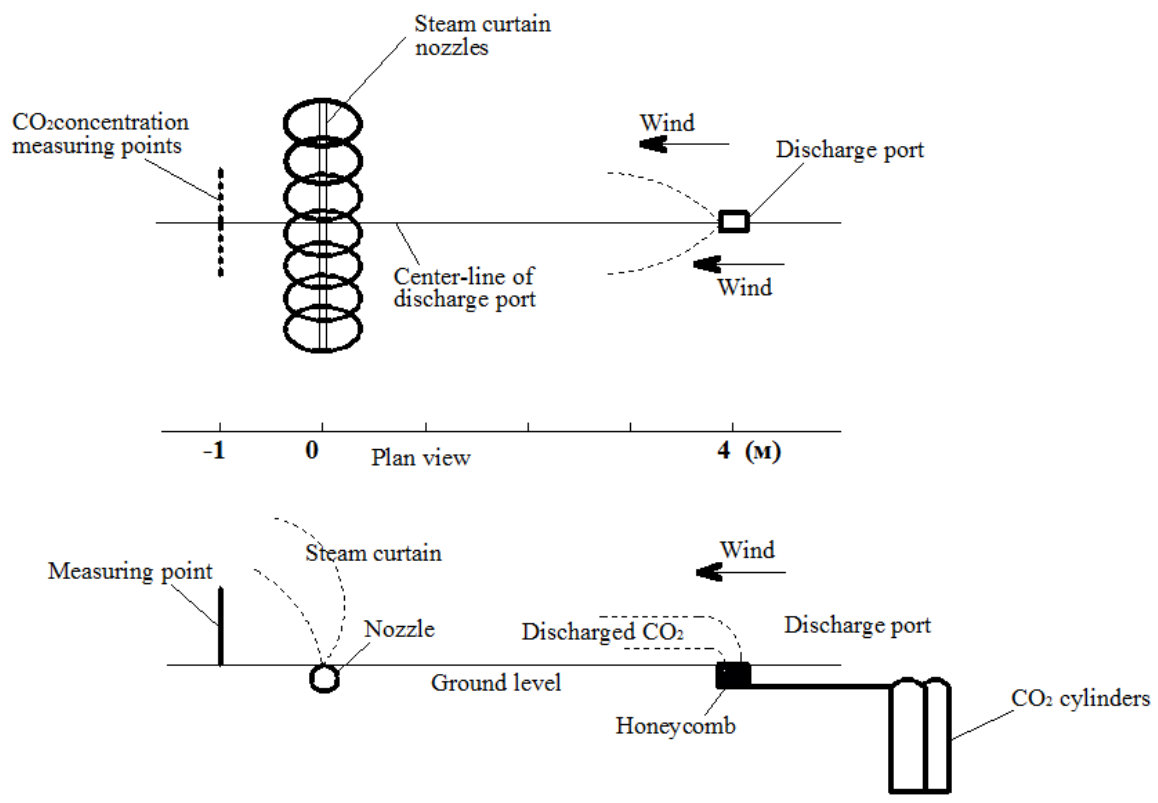

Fig. 1. Schematic representation of a laboratory installation.

To the equations of conservation mass and the chemical component, describing the given group of cells, the terms of the source, corresponding to the value of the rate of carbon dioxide, are added. In the same way, we simulate a curtain: select a group of cells on the lower face in the form of a line with the appropriate length and location, set the values of the mass flow of the steam curtain in the terms of the source in the equation of continuity and conservation chemical component. Before setting the mass flow of steam, it is necessary to determine the nature and regime of the curtain flow through the nozzles. This problem was solved using the methods, described in the paper [2], which takes into account the area of the holes from which the steam escapes outward, the state of the steam in the supply pipeline (pressure, density, temperature, etc.). All the calculated values necessary for further calculating the mass velocity of steam are expressed in Table 1. According to the steam discharging regime (supersonic motion at the nozzle outlet), the mass flow was determined by the equation:

$$
q=S \cdot \mu\left[P_{2} \cdot \rho_{2} \cdot\left(\frac{2}{\gamma+1}\right)^{(\gamma+1) /(\gamma-1)}\right]^{1 / 2}
$$

where $q$ - mass flow rate of steam, $\mathrm{kg} / \mathrm{s} ; S$ - nozzle orifice area, $\mathrm{m}^{2} ; \rho_{2}$ - vapor density at temperature and pressure in the steam pipeline, $\mathrm{kg} / \mathrm{m}^{3} ; \mu$-discharge coefficient ( $\mu=0,3$ default); $\gamma$ - the adiabat exponent. 
Table 1. Calculated parameters of the steam curtain flow.

\begin{tabular}{|l|c|c|}
\hline \multirow{2}{*}{ Curtain parameters } & $\begin{array}{c}\text { Steam } \\
\text { pressure }\end{array}$ & Value \\
\hline Mass flow rate $\mathrm{q}, \mathrm{kg} / \mathrm{s}$ & $3 \mathrm{kgf} / \mathrm{cm}^{2}$ & 0,0187 \\
\cline { 2 - 3 } & $5 \mathrm{kgf} / \mathrm{cm}^{2}$ & 0,0306 \\
\hline Steam temperature, $K$ & $3 \mathrm{kgf} / \mathrm{cm}^{2}$ & 406 \\
\cline { 2 - 3 } & $5 \mathrm{kgf} / \mathrm{cm}^{2}$ & 425 \\
\hline The adiabat exponent $\gamma$ & $3 \mathrm{kgf} / \mathrm{cm}^{2}$ & \multirow{2}{*}{1,31} \\
\cline { 2 - 3 } & $5 \mathrm{kgf} / \mathrm{cm}^{2}$ & 0,34 \\
\hline$\frac{P_{0}}{P_{2}}$ & $3 \mathrm{kgf} / \mathrm{cm}^{2}$ & 0,2 \\
\hline \multirow{2}{*}{$\left(\frac{2}{\gamma+1}\right)^{\gamma /(\gamma-1)}$} & $5 \mathrm{kgf} / \mathrm{cm}^{2}$ & 0,2 \\
\cline { 2 - 2 } & $3 \mathrm{kgf} / \mathrm{cm}^{2}$ & \multirow{2}{|c}{0,54} \\
\cline { 2 - 2 }
\end{tabular}

where $P_{0}$ - ambient pressure. The initial turbulence parameters for gas emission sources, wind and steam flows, were the hydraulic diameter and intensity of turbulence. The last parameter can be approximately calculated by the equation:

$$
I=\frac{v^{\prime}}{v_{\text {aver }}}=0,16\left(\operatorname{Re}_{D_{H}}\right)^{-1 / 8}
$$

where $I$ - intensity of turbulence, $\%$; $v^{\prime}-$ the pulsating velocity of the flow, $\mathrm{m} / \mathrm{s} ; v_{\text {aver }}$ averaged velocity of the flow, $\mathrm{m} / \mathrm{s} ; R e_{D H}$ - the Reynolds number of the moving flow. The vapor density and the gases, participating in the experiment, were calculated from the equation of state of an ideal gas:

$$
\rho=\frac{P}{R \cdot T}
$$

where $\rho$ - substance flow density, $\mathrm{kg} / \mathrm{m}^{3} ; P$ - substance flow pressure, $\mathrm{Pa} ; R$ - universal gas constant, $\mathrm{J} / \mathrm{kg} ; T$ - flow temperature, $\mathrm{K}$.

\section{Calculation results and conclusions}

Numerical simulation of the steam curtain protection was carried out in full accordance with real experiment conditions, for which a three-dimensional grid area space was constructed in accordance with the geometry and location of individual elements of the installation. The boundary and initial conditions for the steam curtain were established in accordance with the calculated parameters reflected in Table 1, the initial turbulent characteristics, temperature, flow velocity for the air curtain, ambient air, and the source of carbon dioxide emission, according to the information, described in the previous paragraph of this article. The results of full-scale and numerical experiments are shown in Figures 2 and 3 . 


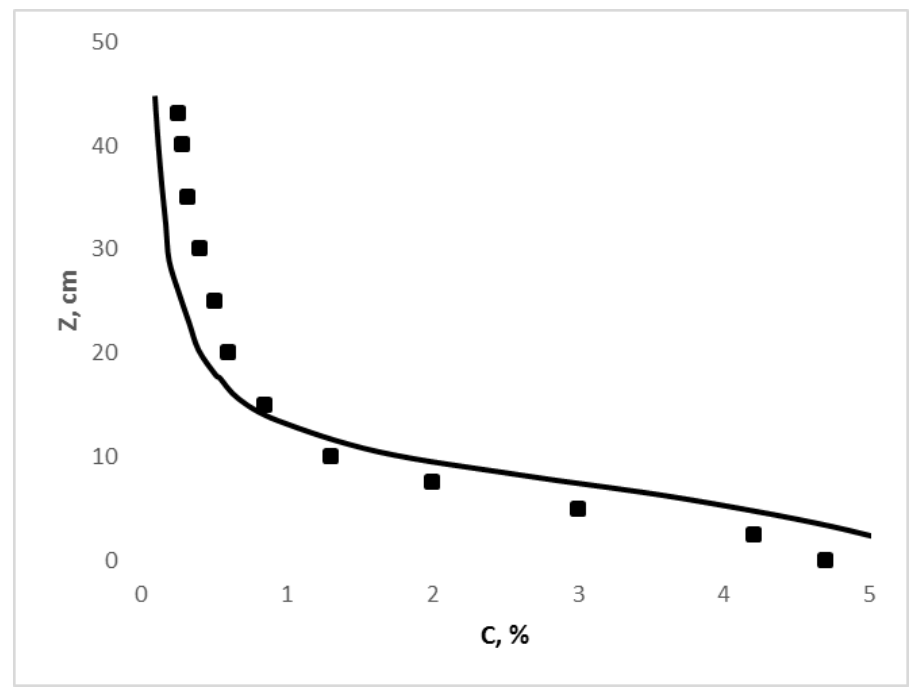

a

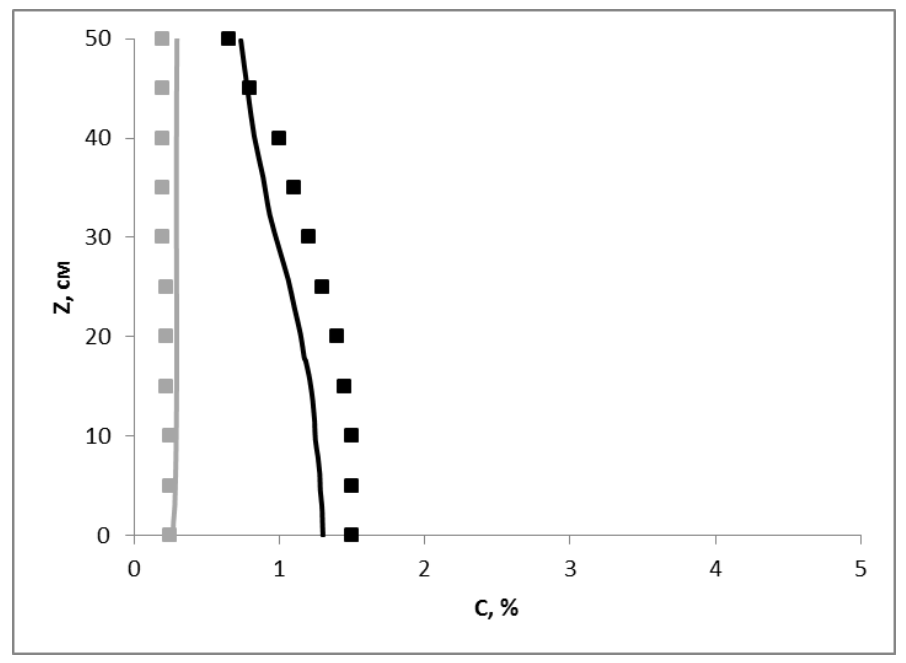

b

Fig. 2. Measured and calculated concentrations of carbon dioxide after the curtain in the vertical direction: $\mathrm{a}$ - without the protective curtain; $\mathrm{b}$ - with a functioning steam barrier.

The dots in the figures show the experimental values of measured concentrations of $\mathrm{CO}_{2}$, solid lines - calculated, using a mathematical model, concentrations. In Figures 2 and 3 , under the letter $b$, the black color indicates the data belonging to the experiment with a curtain, in which the steam pressure in the supply line is $3 \mathrm{kgf} / \mathrm{cm}^{2}$, the gray color is a curtain, with a steam pressure of $5 \mathrm{kgf} / \mathrm{cm}^{2}$. 

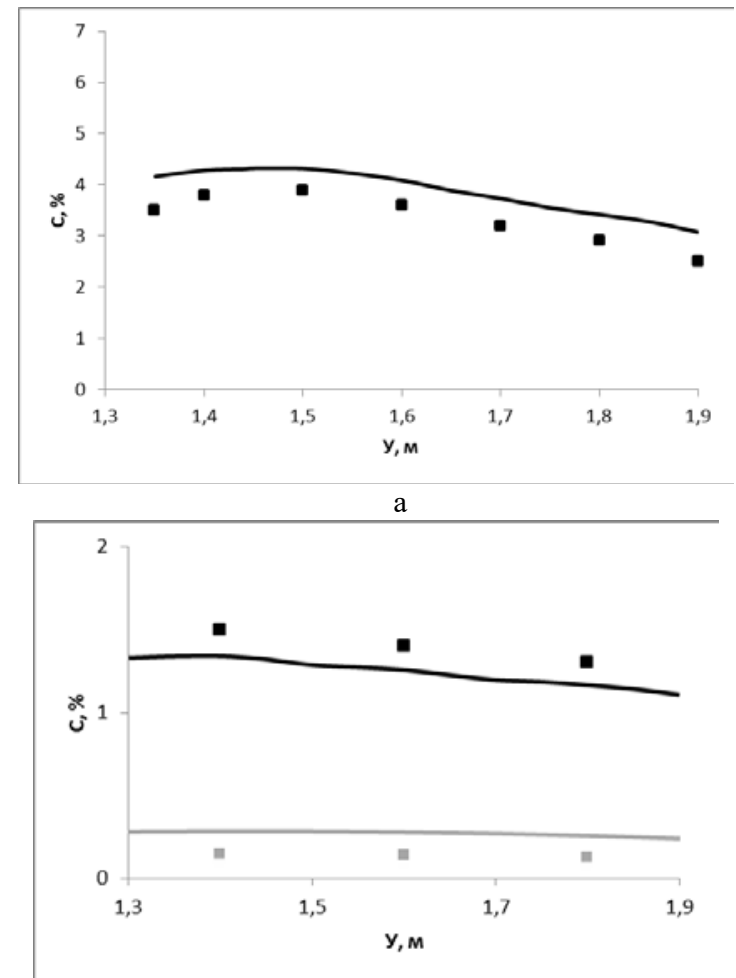

$\mathrm{b}$

Fig. 3. Measured and calculated concentrations of carbon dioxide after the curtain in the horizontal direction: $\mathrm{a}$ - without the protective curtain; $\mathrm{b}$ - with a functioning steam barrier.

The illustrations of the calculated results from the developed model indicate its good convergence with the measured $\mathrm{CO}_{2}$ concentrations of the full-scale experiment. The greatest divergence between calculation and experiment does not exceed $13 \%$, which is quite acceptable and permissible for the target use of the model. The divergences were obtained as a result of the influence many factors, such as: errors in the methods of conducting a physical experiment, errors in measuring instruments, errors of the researchers who conducted the experiment, the abstraction of the mathematical model (neglecting certain aspects of the real processes under investigation), etc. In the future, in order to more thoroughly verify the developed mathematical model, it is necessary to compare the results of predicting the efficiency of the steam curtain with the results of the other researchers experiments again.

\section{References}

1. S. A. Akhmetov, T. P. Serikov and I. R. Kuzeev, Technology and equipment of oil and gas refining processes [in Russian] (Nedra, St Petersburg, 2006)

2. Order of the Ministry of Emergency Situations of the Russian Federation of 10 July 2009 No. 404 "On the approval of the methodology for determining the calculated values of fire risk at production facilities."

3. Kimio Sato, J LOSS PREVENT PROC, 2, 209-214, (1989)

4. Fluent Inc. Fluent 6.1. User's Guide, Lebanon (2003) 